\title{
DESENVOLVIMENTO DE SOFTWARE DE BALANÇO TÉRMICO DE FORNOS DE REAQUECIMENTO DE PLACAS INTEGRADO COM SISTEMA DE CONTROLE*
}

Cristóvão Nery Giacomin ${ }^{1}$ Jean Viana Bahia ${ }^{2}$ Antônio Adel dos Santos ${ }^{3}$ Arthur de Castro Souza ${ }^{4}$

\section{Resumo}

Foi desenvolvido um software para cálculo do balanço térmico dos fornos de reaquecimento de placas da Usiminas em Ipatinga. Ele realiza a busca automática de dados operacionais e das placas reaquecidas, valida, trata os dados e realiza os cálculos das parcelas de entrada e saída dos aportes térmicos para cada forno. Além disso, são calculados o rendimento, a eficiência térmica e o índice de ocupação dos fornos. O desenvolvimento foi realizado em ambientes visuais, com utilização de interfaces gráficas para fácil interação dos usuários com o software. A validação do software foi realizada pela comparação de resultados obtidos na busca automática com valores reais operacionais de balanços térmicos já realizados nos fornos.

Palavras-chave: Fornos de reaquecimento; Balanço térmico; Software de balanço térmico; Eficiência térmica.

\section{DEVELOPMENT OF A SOFTWARE FOR THERMAL BALANCE OF SLAB REHEATING FURNACES INTEGRATED WITH CONTROL SYSTEM}

\section{Abstract}

It was developed a software for thermal balance calculations of Usiminas slab reheating furnaces in Ipatinga. It performs automatic data search of operating conditions and reheated slabs, validates and treats the data, and performs the calculation of inlet and outlet thermal parcels for each furnace. Furthermore, are calculated the yield, thermal efficiency, and occupancy rate of furnaces. The development was carried out in visual environments, with the use of graphical interfaces to ease interaction of users with the app. The software validation was performed by comparison of the results obtained in automatic search with operational values obtained in previous thermal balances performed in the furnaces.

Keywords: Reheating furnaces; Thermal balance; Thermal balance software; Thermal efficiency.

1 Analista de Sistemas, MBA, Analista de Processos Pleno, Gerência Técnica de Laminações, Usiminas, Ipatinga, MG.

2 Engenheiro Químico, Pesquisador Pleno, Centro de Pesquisa e Desenvolvimento da Usiminas, Ipatinga, MG.

3 Engenheiro Metalurgista, D.Sc., CQE/ASQ, Pesquisador Especialista Sênior, Centro de Pesquisa e Desenvolvimento da Usiminas, Ipatinga, MG.

4 Engenheiro Metalurgista, Engenheiro de Produção Pleno, Gerência Técnica de Laminações, Ipatinga, MG. 


\section{INTRODUÇÃO}

O balanço térmico de fornos de reaquecimento é uma metodologia importante para avaliação de desempenho operacional, através, principalmente, da disponibilização de valores de eficiência térmica e de rendimento teórico dos fornos. O balanço é utilizado para diagnose da eficiência térmica de fornos, permitindo avaliar as parcelas de entrada e saída de calor, fornecendo subsídios para a redução do consumo de combustíveis. Por não ser uma ferramenta de controle nem de simulação, o balanço é aplicado a um período operacional passado, preferencialmente quando o forno opera em regime estacionário, quando a massa das placas enfornadas é próxima à das placas desenfornadas.

$\mathrm{Na}$ Usiminas, realizam-se balanços térmicos nos fornos de reaquecimento de placas desde a década de 80 [1]. Isso contribuiu significativamente para o aprimoramento da aplicação desta metodologia na empresa.

Tradicionalmente, a realização do balanço térmico requer a mobilização de uma equipe grande para levantamento de dados operacionais dos fornos e das placas processadas, a amostragem dos combustíveis e fumaça. $O$ elevado volume de dados e a necessidade de cautelosa avaliação de sua integridade, seguida de seu tratamento, tornava demorada e custosa a execução do balanço. Foi justamente para simplificar tais tarefas que foi introduzido o balanço no sistema automático [2] dos fornos da linha de Laminação de Tiras a Quente (LTQ). No entanto, este balanço não supria todas as necessidades dos fornos de Ipatinga, primeiro por não contemplar os fornos da linha de Laminação de Chapas Grossas (LCG), e segundo, por necessitar de melhor tratamento e validação dos dados aquisitados.

Diante desse cenário, foi desenvolvido o software de cálculo do balanço térmico dos fornos. As principais premissas do projeto foram: (i) atender tanto a LCG como a LTQ; (ii) fazer a busca automática dos dados necessários de operação dos fornos e das placas processadas; (iii) o tratamento desses dados e; (iv) o cálculo automático do balanço. Outra premissa era que a apresentação dos resultados fosse desenvolvida em interfaces de fácil interpretação, para viabilizar seu uso pelas equipes técnica e operacional.

\section{MATERIAIS E MÉTODOS}

\subsection{Forno de reaquecimento}

$\mathrm{Na}$ laminação a quente de produtos planos, os fornos de reaquecimento têm como finalidade principal elevar a temperatura das placas para conferir a plasticidade necessária para conformação e dissolver os precipitados de elementos microligantes existentes, para permitir sua laminação até a dimensão desejada.

Os fornos contínuos de reaquecimento de placas podem ser classificados em função do método de deslocamento das placas e do seu formato da seguinte maneira:

- fornos de soleira fixa (pusher furnace);

- fornos de vigas caminhantes (walking beam furnace);

- fornos com soleira móvel (walking hearth furnace);

- fornos com mesas de rolos ou fornos túnel.

$\mathrm{Na}$ Usina de Ipatinga, há um forno pusher, o forno 3 da LTQ, que possui 3 zonas (duas de aquecimento e uma de encharque), e 4 fornos walking beam (apresentados 
esquematicamente na Figura 1), os fornos 1 e 2 da LCG e os fornos 4 e 5 da LTQ, que possuem 6 zonas (duas de pré-aquecimento, duas de aquecimento e duas de encharque). As principais características destes fornos são apresentadas na Tabela 1.

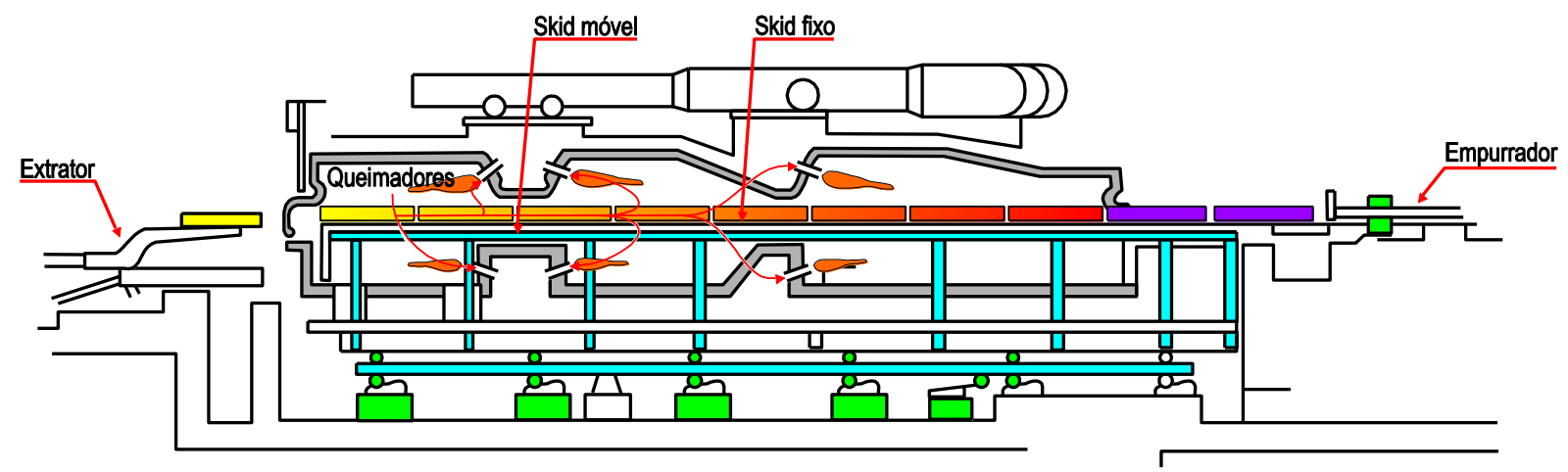

Figura 1. Corte longitudinal de um forno tipo walking beam [3].

Tabela 1. Fornos de reaquecimento de placas da Usina de Ipatinga e suas características.

\begin{tabular}{|c|c|c|c|c|c|c|}
\hline $\begin{array}{c}\stackrel{N}{N} \\
\text { FORNO }\end{array}$ & LINHA & TIPO & $\begin{array}{c}\text { № DE } \\
\text { ZONAS }\end{array}$ & AUTOMAÇÃO & COMBUSTÍVEIS & $\begin{array}{c}\text { PRODUÇÃO } \\
(\mathrm{T} / \mathrm{H})\end{array}$ \\
\hline 1 & \multirow{2}{*}{$\begin{array}{l}\text { Chapas } \\
\text { Grossas }\end{array}$} & $\begin{array}{c}\text { Walking } \\
\text { Beam }\end{array}$ & 6 & Total & COG, Óleo & 130 \\
\hline 2 & & $\begin{array}{c}\text { Walking } \\
\text { Beam }\end{array}$ & 6 & Total & COG, Óleo & 130 \\
\hline 3 & \multirow{3}{*}{$\begin{array}{l}\text { Tiras a } \\
\text { Quente }\end{array}$} & Pusher & 3 & Parcial & \multirow{3}{*}{$\begin{array}{c}\text { COG, BFG, LDG, } \\
\text { Óleo, } \\
\text { GN }\end{array}$} & 100 \\
\hline 4 & & $\begin{array}{c}\text { Walking } \\
\text { Beam }\end{array}$ & 6 & Total & & 230 \\
\hline 5 & & $\begin{array}{c}\text { Walking } \\
\text { Beam }\end{array}$ & 6 & Total & & 230 \\
\hline
\end{tabular}

*COG:Gás de coqueria; BFG: Gás de altos-fornos; LDG: Gás de aciarias; GN: Gás natural.

\subsection{Balanço térmico}

O balanço térmico consiste da comparação das parcelas de energia que entram e saem de um processo num determinado período, preferencialmente em regime estável de operação. Um balanço térmico é importante para avaliar a eficiência energética de um processo e determinar os principais pontos de perda de energia.

Em um forno de reaquecimento de placas existem diversas parcelas de entradas e saídas de energia, porém, espera-se que a maior parte da energia inserida no processo pela combustão dos combustíveis saia nas placas reaquecidas.

As parcelas de energia em um balanço térmico são subdivididas em dois grupos: entradas e saídas. Evidentemente, a soma de todas as parcelas de energia de entrada deve ser igual à soma de todas as parcelas de saída, no regime estacionário. Porém, apesar de todo o rigor que se pode aplicar a um balanço térmico, sempre existem parcelas de energia não consideradas e erros de aproximação. Neste caso usa-se uma parcela de saída chamada "Outros" que é a diferença entre o somatório dos calores de entrada e dos de saída. 


\subsection{Desenvolvimento do software do balanço}

Foi desenvolvida uma solução que contém projetos para realização da busca automática e tratamento dos dados, projetos de interfaces gráficas, que são utilizadas pelo usuário para interação com o software do balanço térmico e, por fim, o projeto para cálculos do balanço térmico.

Uma visão geral das funções do software do balanço térmico desenvolvido é mostrada na Figura 2.

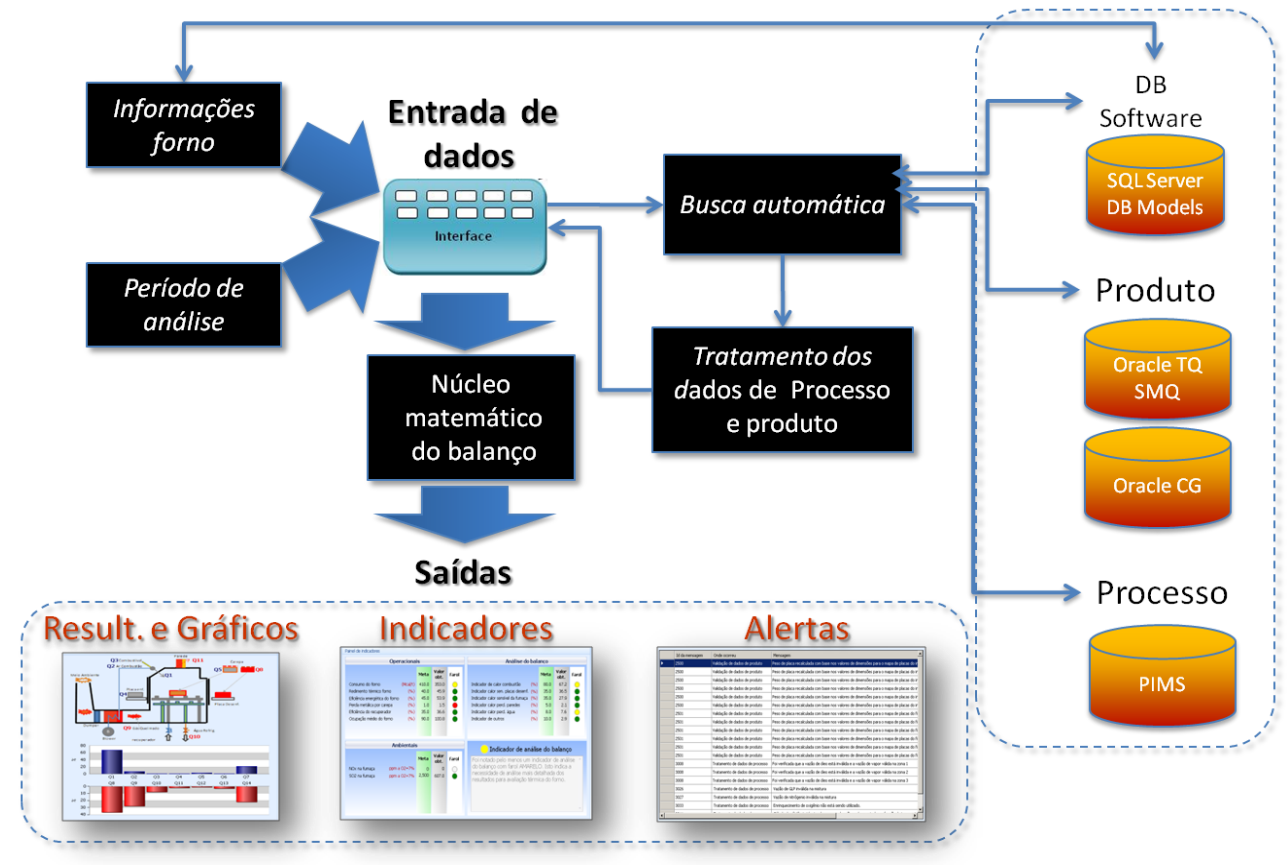

Figura 2. Visão geral das funções do software do balanço térmico desenvolvido.

Foram desenvolvidos 3 modos de cálculo do balanço: (i) manual, onde todas as entradas devem ser realizadas manualmente; (ii) semiautomático, onde alguns dados serão entrados manualmente; e (iii) automático, onde a busca de dados é totalmente automática.

\subsection{Busca automática e tratamento de dados}

O processo de busca automática de dados consiste em levantar um conjunto de dados operacionais dos fornos de reaquecimento e das placas aquecidas, nos bancos de dados mantidos pela automação, no período considerado.

Este processo é disparado pelo usuário a partir da interface de entrada de dados, para um forno previamente selecionado. Isso é realizado utilizando a interligação entre a rede coorporativa da TI e a rede dedicada da automação, conforme mostrado, de forma esquemática, na Figura 3.

Neste software, distinguiram-se variáveis de processo, que são dados operacionais dos fornos, e variáveis de produtos, que são relacionadas a dimensões, composições químicas e temperaturas das placas processadas no período do balanço térmico. Esta distinção é necessária, pois estas informações estão em bancos de dados diferentes.

O processo de busca consiste da aquisição de dados nas bases disponíveis no formato digital, armazenadas em bancos de dados como o PIMS [4] e o Oracle. Esta 
busca é iniciada a partir de variáveis cadastradas em um banco de dados desenvolvido [5] para suportar este software.

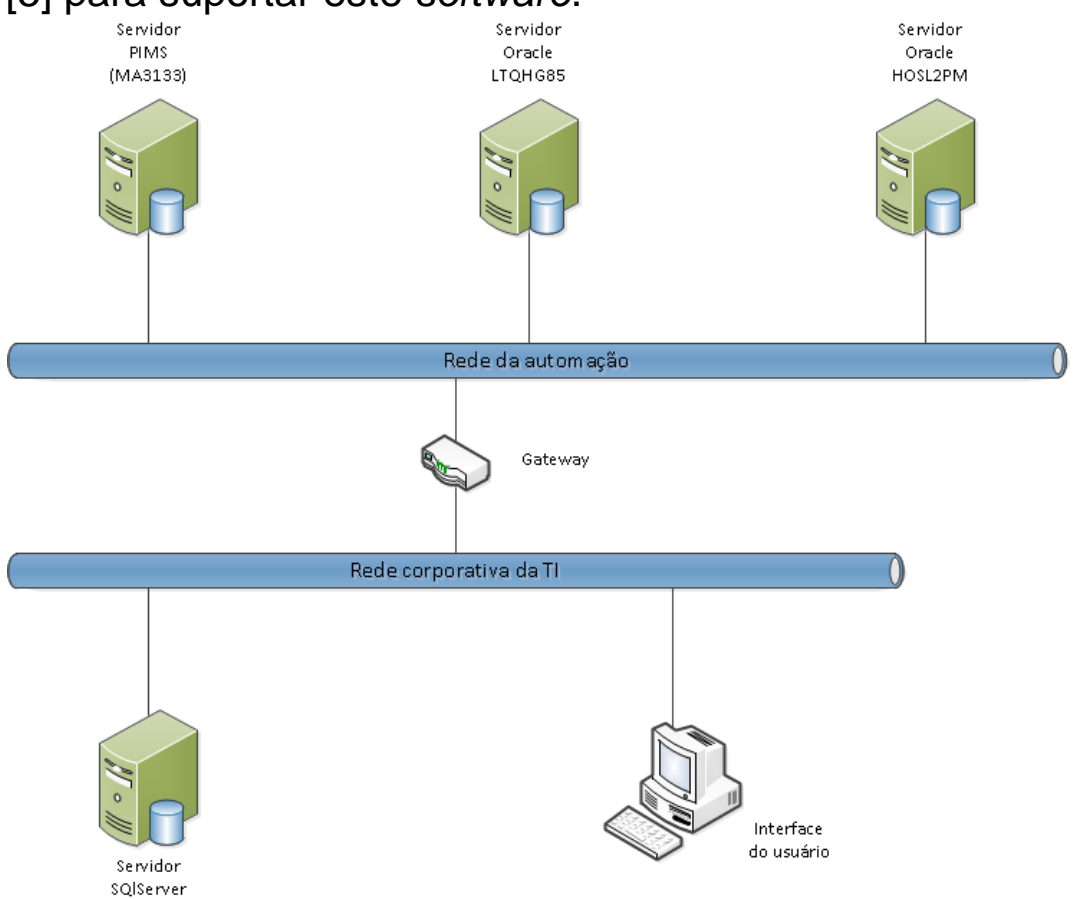

Figura 3. Representação esquemática dos recursos de rede utilizados na busca automática.

Os dados obtidos das bases são armazenados em varáveis digitais (VD). Para serem utilizados nos cálculos do balanço, estes dados são tratados e armazenados em variáveis padrão (VP). A VP é toda variável de entrada necessária para o cálculo do balanço térmico. Ela pode ser digital, quando recebe os dados validados e tratados automaticamente, ou analógica, quando sua entrada é manual. Cada VP é associada a uma ou mais VD, por critério de afinidade [6], conforme esquema da Figura 4.

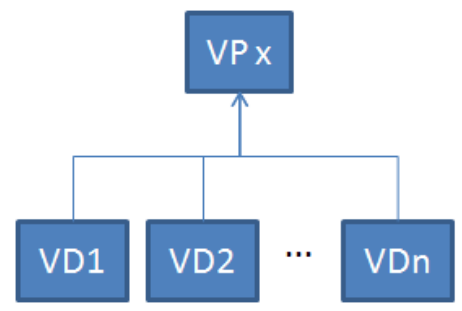

Figura 4. Representação da configuração de uma VP.

\subsection{Interfaces gráficas do software do balanço térmico}

As interfaces para o software do balanço térmico foram desenvolvidas privilegiando a usabilidade, a flexibilidade de acesso e o design leve. A plataforma utilizada para o desenvolvimento foi a do Microsoft Visual Studio 2008. Foram desenvolvidas, ao todo, 33 interfaces gráficas para implementar as necessidades deste software. Nas Figuras de 5 a 14 são apresentadas a interface principal, a de cadastro do forno, a de entrada de dados, a de configuração de VP e as interfaces de saída de resultados. 


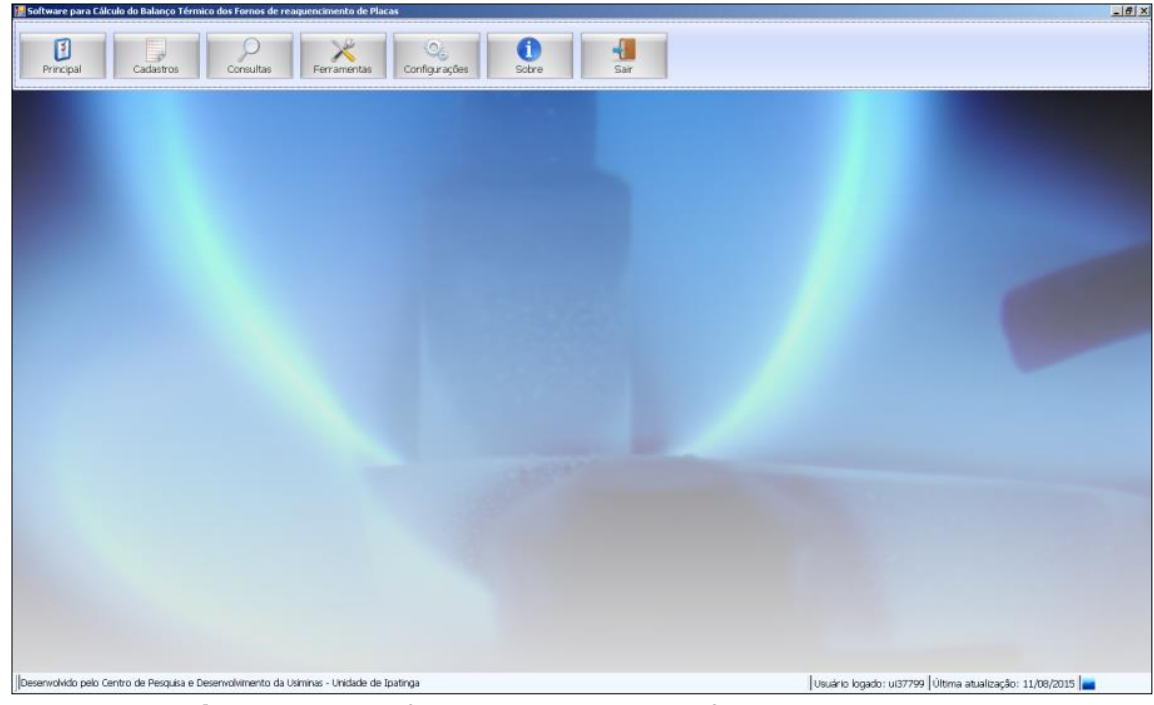

Figura 5. Interface principal no software do balanço.

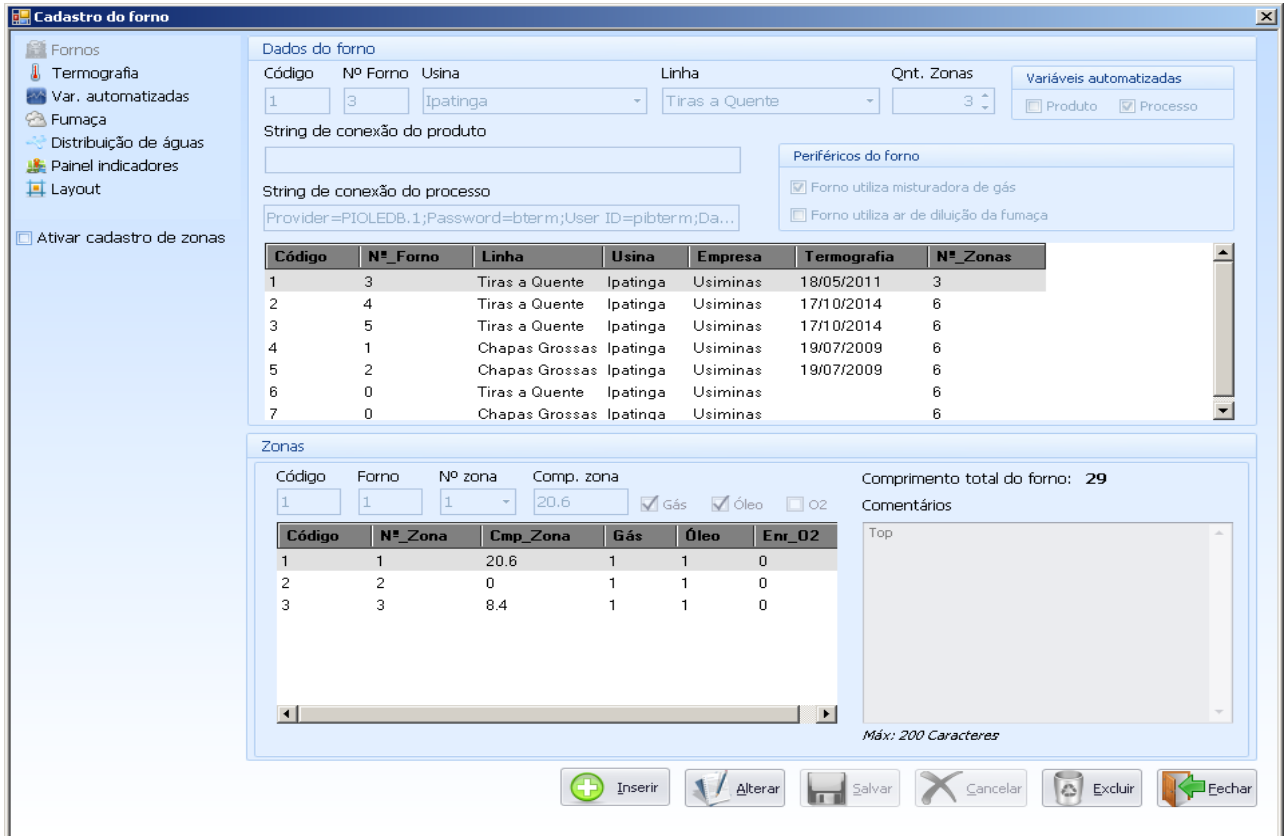

Figura 6. Interface de cadastro do forno, com foco no menu Fornos.

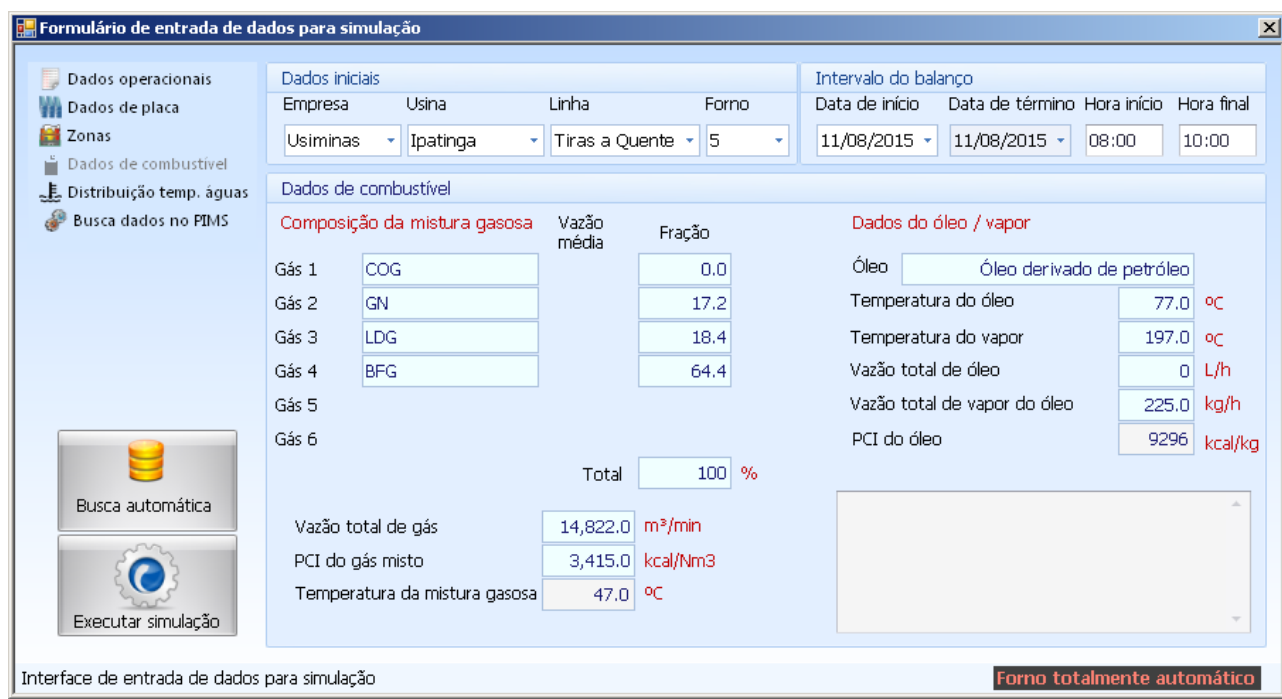

Figura 7. Interface de dados de entrada, menu, "Dados combustíveis" no modo automático. 


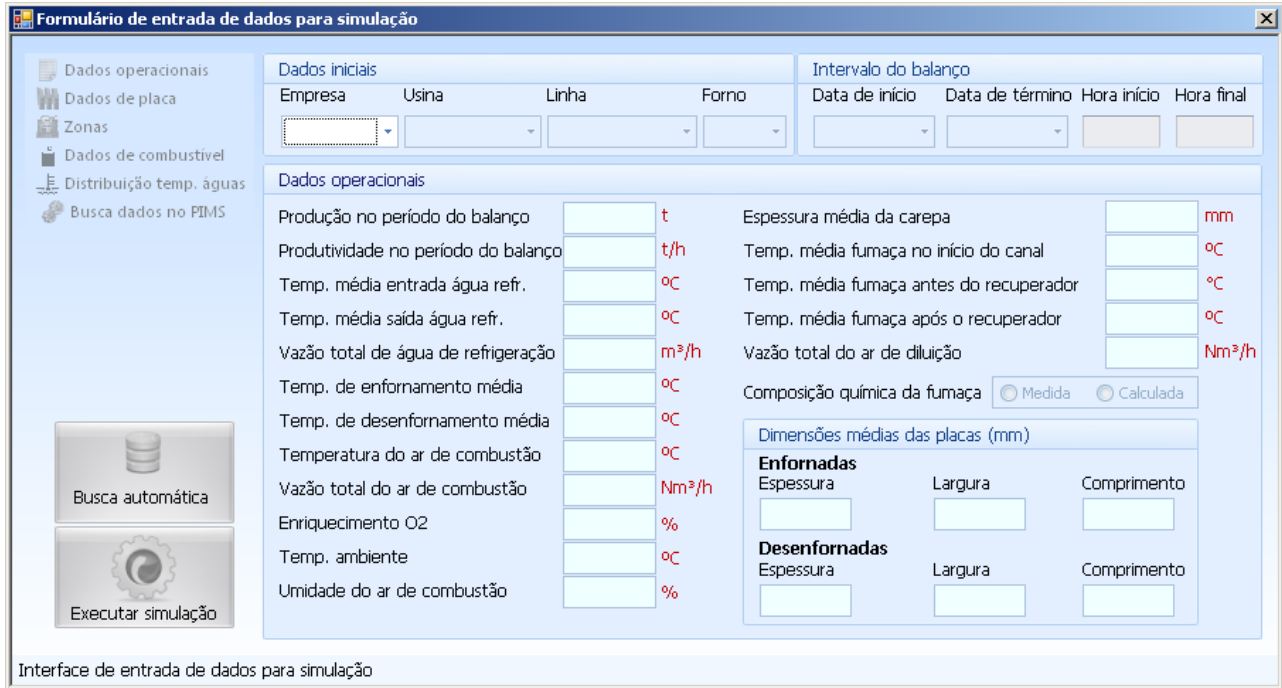

Figura 8. Interface de entrada de dados para cálculo do balanço.

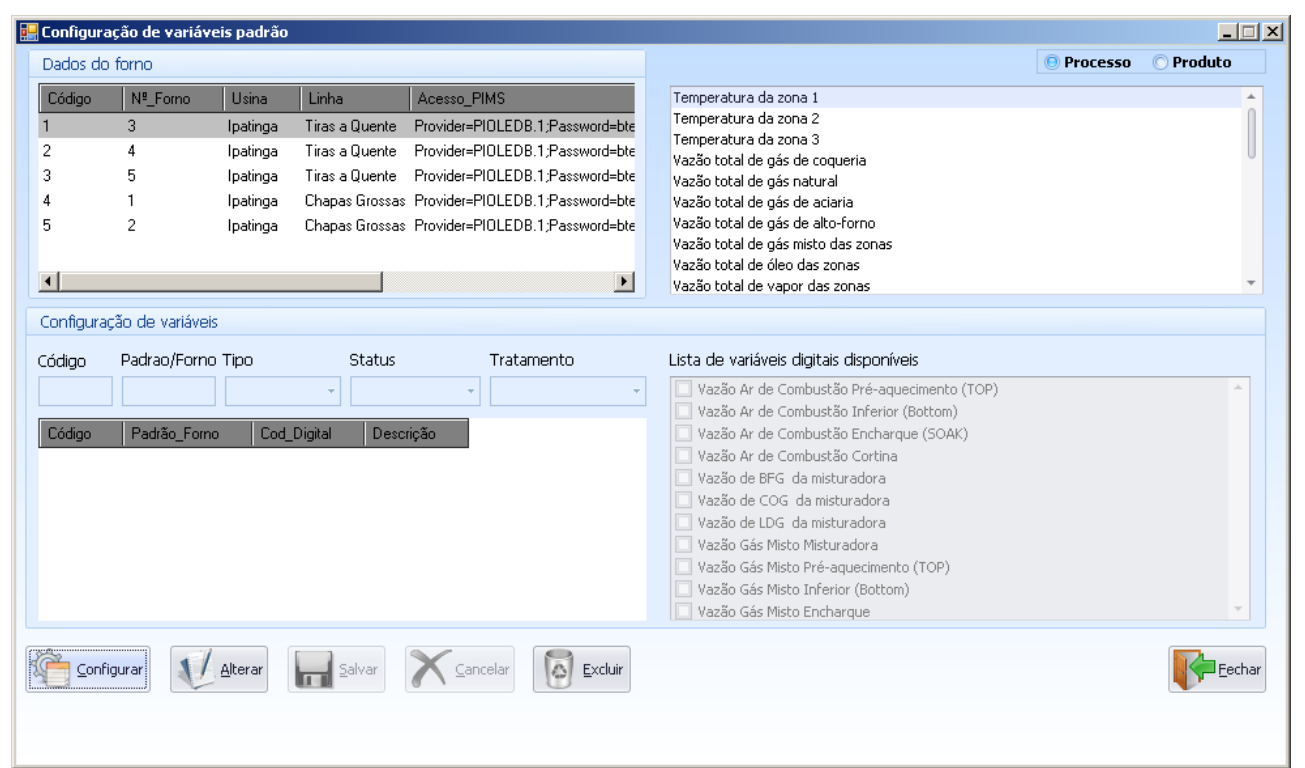

Figura 9. Interface de configuração da VP.

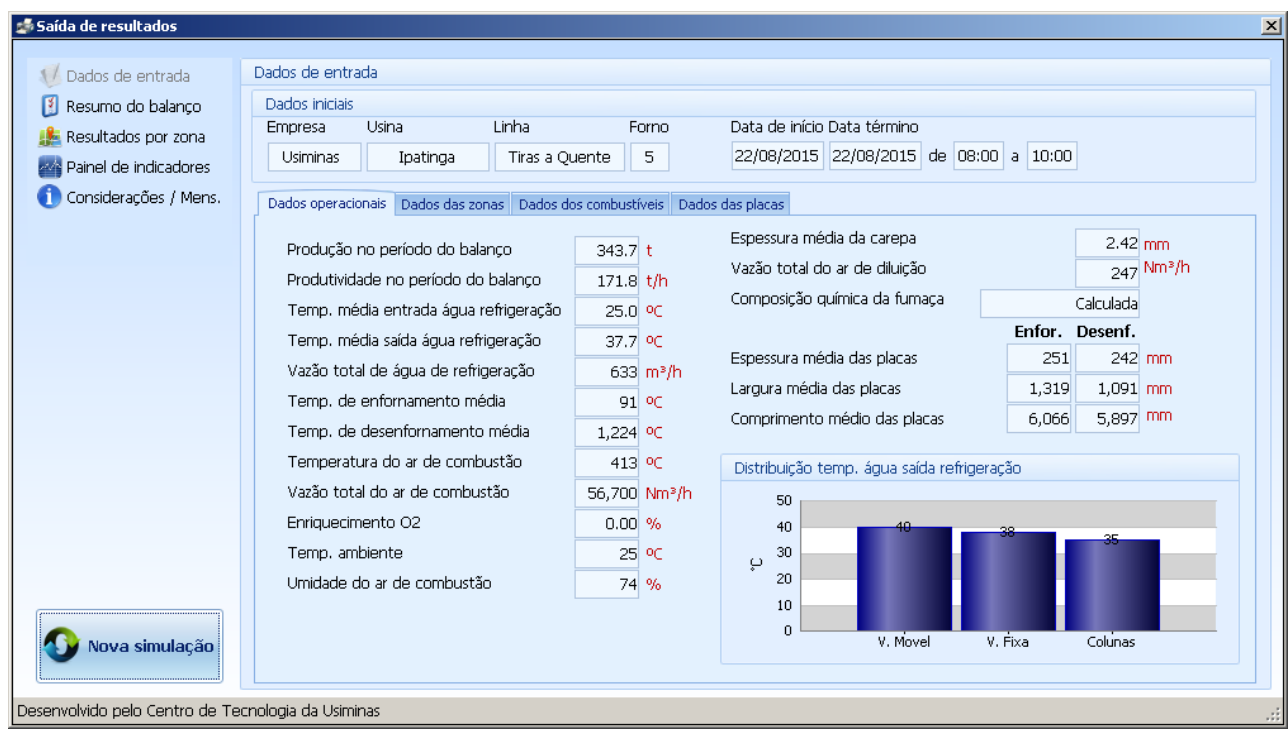

Figura 10. Interface de saída de resultados, menu Dados de entrada, guia de dados operacionais. 


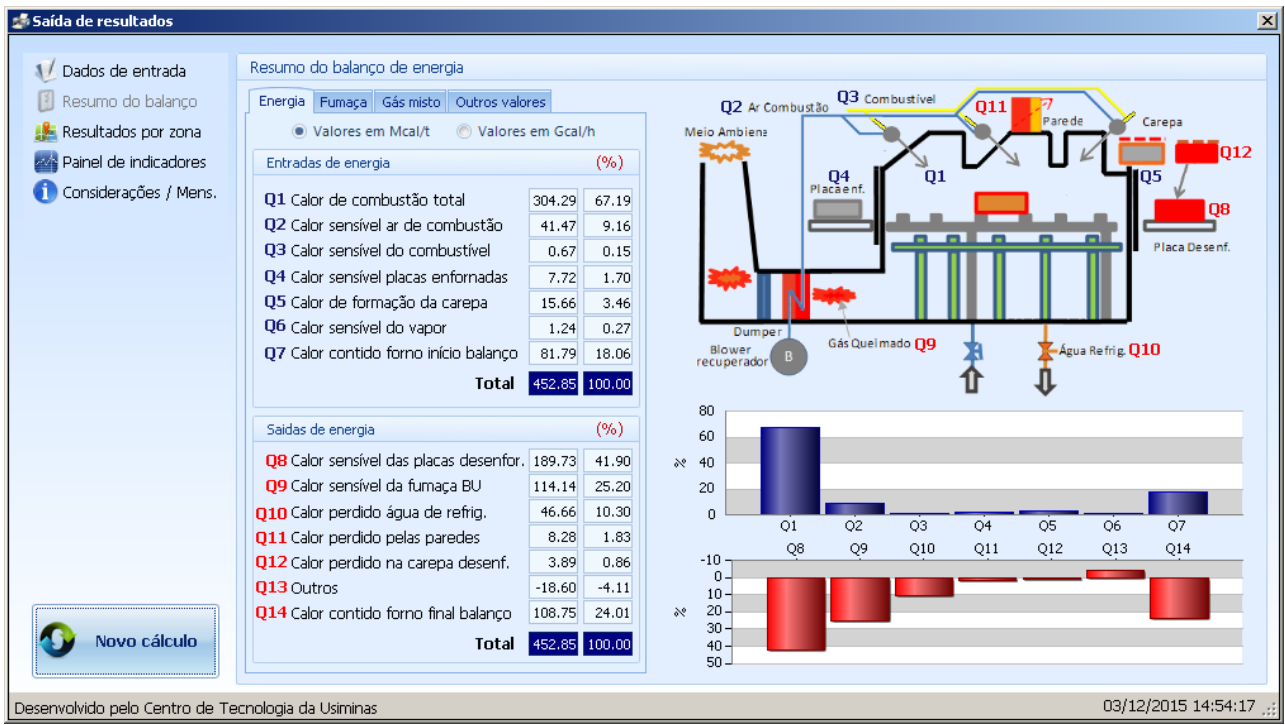

Figura 11. Interface de saída de resultados, menu Resumo do balanço, guia energia.

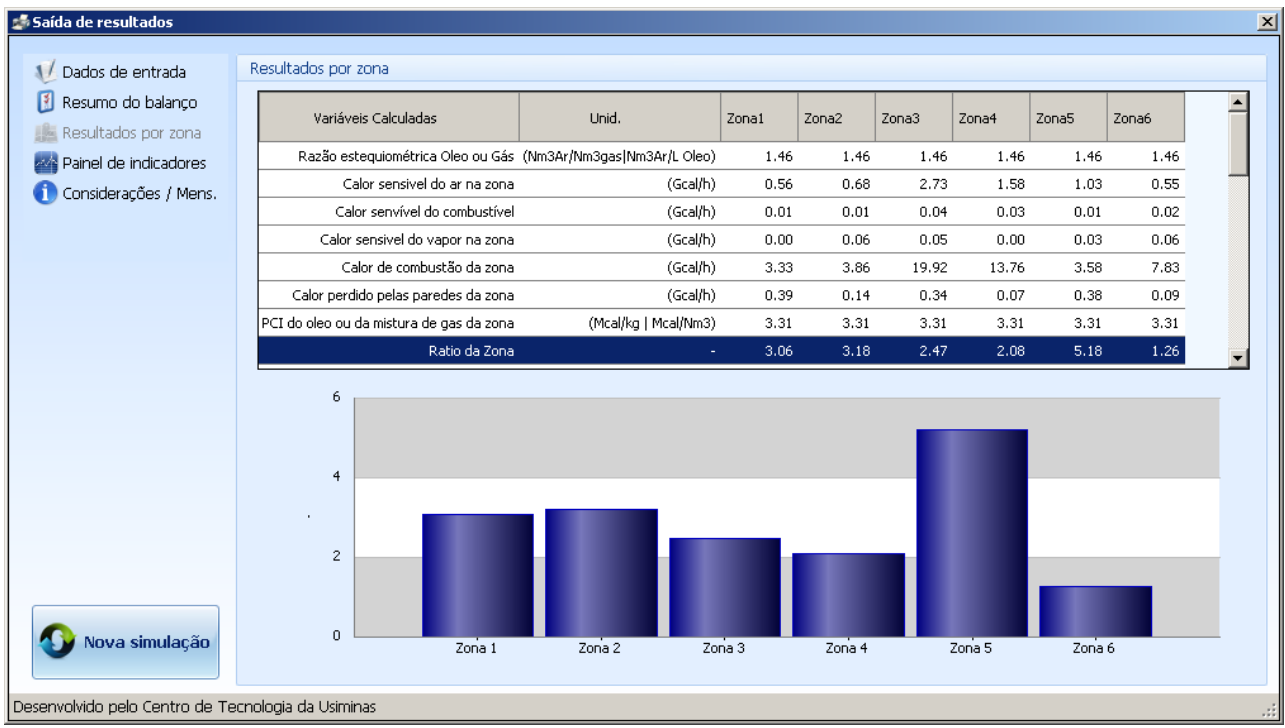

Figura 12. Interface de saída de resultados, menu Resultados por zona.

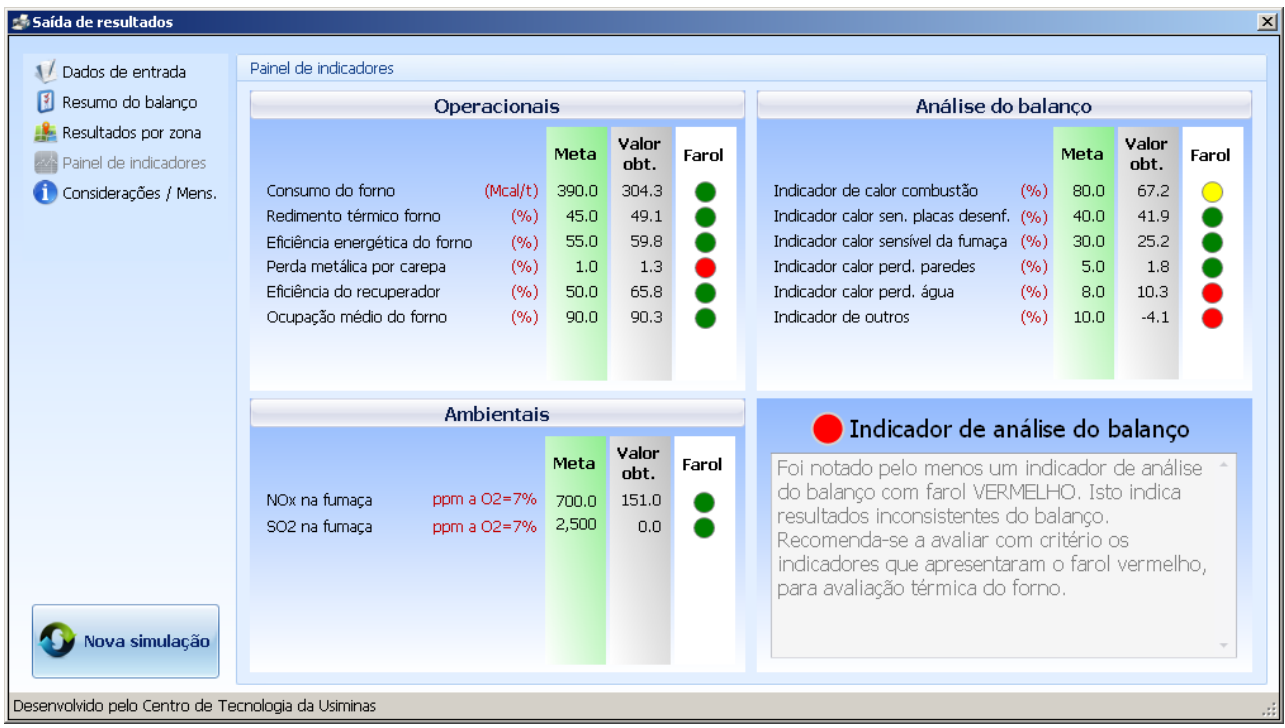

Figura 13. Interface do painel de indicadores na saída resultados. 


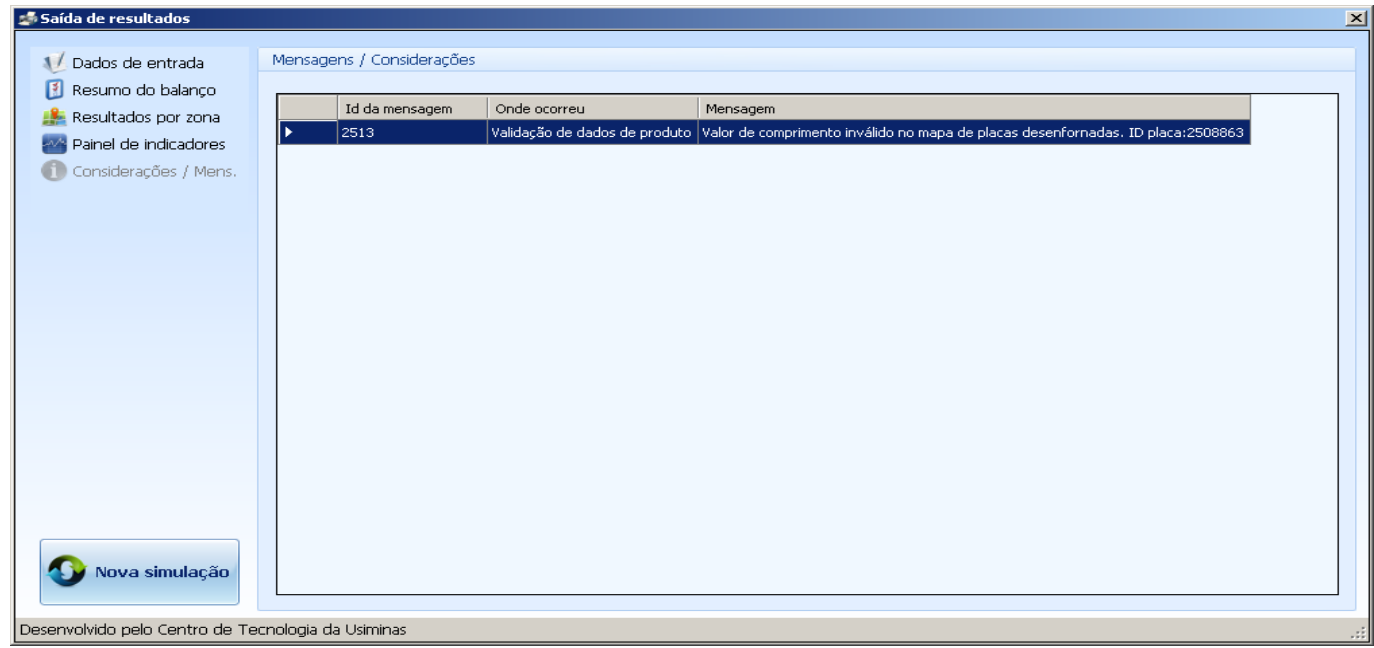

Figura 14. Interface de mensagens e considerações na saída resultados.

\section{RESULTADOS E DISCUSSÃO}

\subsection{Cálculo do Balanço Térmico}

Neste software foi convencionado que as parcelas de calor de entrada são identificadas de Q1 a Q7 e as de saída de Q8 a Q14, conforme mostrado na Tabela 2.

Tabela 2. Parcelas de energia consideradas no balanço desenvolvido.

\begin{tabular}{llcl}
\hline \multicolumn{2}{c}{ ENTRADAS } & & \multicolumn{1}{c}{ SAÍDAS } \\
\hline Q1 & Calor de combustão & Q8 & Calor sensível das placas desenfornadas \\
\hline Q2 & Calor sensível do ar de combustão & Q9 & Calor sensível da fumaça \\
\hline Q3 & Calor sensível dos combustíveis & Q10 & Calor perdido por água de refrigeração \\
\hline Q4 & Calor sensível das placas enfornadas & Q11 & Calor perdido por paredes \\
\hline Q5 & Calor de formação de carepa & Q12 & Calor perdido na carepa desenfornada \\
\hline Q6 & Calor sensível do vapor de atomização & Q13 & Outros \\
\hline Q7 & Energia contida no forno no início do balanço & Q14 & Energia contida no forno no final o balanço \\
\hline
\end{tabular}

Vale ressaltar que Q7 e Q14 não são parcelas de entrada e saída propriamente, mas sim a energia interna total das placas que estão no forno no início e no fim do balanço. Se o regime é muito próximo do estacionário, fato desejável no balanço térmico, os valores destas parcelas serão bem próximos. Eles são introduzidos pois, na realidade, o regime de operação dos fornos não é estacionário, sendo necessário o cálculo destas parcelas para um melhor fechamento do balanço.

Outra particularidade neste software é o cálculo da temperatura adiabática de chama. Trata-se de um valor teórico obtido considerado que toda energia gerada na combustão é usada para aquecer os gases de combustão em um queimador antes de haver troca de calor da chama com o ambiente externo. Portanto, essa temperatura é chamada de adiabática, pois é como se a combustão ocorresse sem perda de calor para o ambiente externo a ela (adiabaticamente). Pela disponibilidade de todas as variáveis necessárias, este cálculo foi implementado neste software por cada zona, visto que uma zona é composta de diversos queimadores operando nas mesmas condições. 


\subsection{Validação do software do balanço térmico}

O processo de validação do software tomou como referência o último balanço térmico realizado no Forno 4 da Laminação de Tiras a Quente de maneira convencional em 29/05/2012, da Usina de Ipatinga, pela equipe do Centro de Pesquisa e Desenvolvimento. Nele foram levantados todos os dados necessários para avaliação térmica do forno. No mesmo período, foi realizada a busca de dados, utilizando o software desenvolvido, executado os tratamentos e, em seguida, os cálculos do balanço. Os valores obtidos tanto na busca de dados automática quanto pelo levantamento do último balanço estão mostrados na Tabela 3.

Tabela 3. Dados de entrada consolidados obtidos na busca automática do software desenvolvido e os obtidos no levantamento de campo.

\begin{tabular}{|c|c|c|c|c|}
\hline VARIÁVEL & UNIDADE & $\begin{array}{l}\text { LEVANTAMENTO } \\
\text { (A) }\end{array}$ & $\begin{array}{l}\text { SOFTWARE } \\
\text { BALANÇO } \\
\text { (B) }\end{array}$ & $\begin{array}{l}\text { DIFERENÇA } \\
\text { (A-B) }\end{array}$ \\
\hline Produção do período & $\mathrm{t}$ & 403,0 & 403,3 & $-0,3$ \\
\hline Tempo de balanço & $\min$ & 120,0 & 124,0 & $-4,0$ \\
\hline Produtividade & $\mathrm{t} / \mathrm{h}$ & 201,5 & 195,1 & 6,4 \\
\hline Temperatura média de enfornamento & ${ }^{\circ} \mathrm{C}$ & 25,0 & 38,7 & $-13,7$ \\
\hline Temperatura média de desenfornamento & ${ }^{\circ} \mathrm{C}$ & 1212,0 & 1211,8 & 0,2 \\
\hline Espessura média da carepa & $\mathrm{mm}$ & 2,84 & 2,47 & 0,4 \\
\hline Espessura média das placas enfornadas & $\mathrm{mm}$ & 244,6 & 244,8 & $-0,2$ \\
\hline Largura média das placas enfornadas & $\mathrm{mm}$ & 1272,1 & 1242,8 & 29,4 \\
\hline $\begin{array}{llll}\begin{array}{l}\text { Comprimento } \\
\text { enfornadas }\end{array} & \text { médio } & \text { das } & \text { placas } \\
\end{array}$ & $\mathrm{mm}$ & 5998,0 & 6006,4 & $-8,4$ \\
\hline $\begin{array}{llll}\begin{array}{l}\text { Espessura média } \\
\text { desenfornadas }\end{array} & \text { das } & \text { placas } \\
\end{array}$ & $\mathrm{mm}$ & 246,6 & 246,6 & 0,0 \\
\hline Largura média das placas desenfornadas & $\mathrm{mm}$ & 1239,4 & 1261,1 & $-21,7$ \\
\hline $\begin{array}{l}\begin{array}{l}\text { Comprimento médio das placas } \\
\text { desenfornadas }\end{array} \\
\end{array}$ & $\mathrm{mm}$ & 5933,4 & 5993,4 & $-60,0$ \\
\hline $\begin{array}{l}\text { Temp. media da água de refrigeração na } \\
\text { entrada }\end{array}$ & ${ }^{\circ} \mathrm{C}$ & 25,0 & 32,0 & 0,0 \\
\hline $\begin{array}{l}\text { Temp. media da água de refrigeração na } \\
\text { saída }\end{array}$ & ${ }^{\circ} \mathrm{C}$ & 45,0 & 45,0 & 0,0 \\
\hline Vazão de água de entrada & $\mathrm{m}^{3} / \mathrm{h}$ & 601,0 & 600,0 & 1,0 \\
\hline Temperatura média do ar de combustão & ${ }^{\circ} \mathrm{C}$ & 344,0 & 344,0 & 0,0 \\
\hline Vazão total do ar de combustão & $\mathrm{Nm}^{3} / \mathrm{h}$ & 73289,0 & 72943,0 & 346,0 \\
\hline Temperatura ambiente & ${ }^{\circ} \mathrm{C}$ & 25,0 & 32,0 & 0,0 \\
\hline Umidade do ar & $\%$ & 74,0 & 74,0 & $-0,3$ \\
\hline Temp. media fumaça entrada recuperador & ${ }^{\circ} \mathrm{C}$ & 886,0 & 884,0 & 2,0 \\
\hline $\begin{array}{l}\text { Temperatura media fumaça saída } \\
\text { recuperador }\end{array}$ & ${ }^{\circ} \mathrm{C}$ & 456,0 & 455,0 & 1,0 \\
\hline Temperatura média do gás misto & ${ }^{\circ} \mathrm{C}$ & 25,0 & 25,0 & 0,0 \\
\hline Vazão total do gás misto & $\mathrm{Nm}^{3} / \mathrm{h}$ & 20478,0 & 18551,0 & 1927,0 \\
\hline PCI do gás misto & $\mathrm{kcal} / \mathrm{Nm}^{3}$ & 3128,0 & 3129,0 & $-1,0$ \\
\hline Temperatura média do óleo & ${ }^{\circ} \mathrm{C}$ & 114,0 & 87,0 & 27,0 \\
\hline Vazão total do óleo & $\mathrm{L} / \mathrm{h}$ & 1089,4 & 1101,0 & $-11,6$ \\
\hline PCI do óleo & $\mathrm{kcal} / \mathrm{kg}$ & 10000,0 & 9296,0 & 704,0 \\
\hline Temperatura média do vapor & ${ }^{\circ} \mathrm{C}$ & 197,0 & 197,0 & 0,0 \\
\hline Vazão total do vapor & $\mathrm{kg} / \mathrm{h}$ & 377,0 & 917,0 & $-540,0$ \\
\hline Fração do COG no GM & $\%$ & 59,7 & 59,7 & 0,0 \\
\hline Fração do BFG no GM & $\%$ & 11,3 & 10,9 & 0,4 \\
\hline Fração do LDG no GM & $\%$ & 29,0 & 29,4 & $-0,4$ \\
\hline
\end{tabular}


As diferenças observadas entre os valores levantados convencionalmente e os obtidos na busca automática no software do balanço foram, em geral, muito pequenas, embora algumas variáveis tenham apresentado diferenças significativas. As mais relevantes são justificadas a seguir.

- Espessura da carepa: o levantamento considerou um valor histórico de 1\% da espessura da placa desenfornada enquanto que o software computa o valor obtido no cálculo do modelo on-line.

- Largura das placas no enfornamento e no desenfornamento: o levantamento considerou a largura prevista; o software, a largura medida no ato do enfornamento.

- Vazão total de gás misto: as informações foram obtidas de origens diferentes. No levantamento foi utilizada a vazão média do gás misto armazenada na base do PIMS (Plant Information Management System); no software do balanço utilizou-se o somatório das médias das vazões das zonas do forno, obtidas no período do balanço. Vale ressaltar que a referência utilizada para cálculo do consumo do forno é o somatório das vazões das zonas.

- Temperatura do óleo: obtida em pontos diferentes de medição.

- Vazão de vapor: o levantamento só contabilizou os valores de vazão da zona que estava utilizando óleo e o software o vapor utilizado em todas as zonas no período, pois mesmo sem queimar óleo, alguma quantidade de vapor é utilizada.

Deve ser ressaltado que os fornos de reaquecimento da LTQ não utilizam óleo combustível atualmente, o qual foi substituído por gás natural.

Para a validação dos cálculos do software, foram alterados alguns valores de entrada para ficarem uniformizados com os utilizados do levantamento. Os valores alterados no software foram: a temperatura ambiente; a umidade do ar; espessura da carepa; $\mathrm{PCl}$ (Poder Calorífico Inferior) do óleo e a temperatura da mistura gasosa. Também foram alterados, nos cálculos do levantamento, alguns parâmetros como: a vazão total de gás foi ajustada para corresponder ao somatório das zonas na busca automática e a densidade do óleo a $20^{\circ} \mathrm{C}$ foi alterada para $1,024 \mathrm{~kg} / \mathrm{L}$.

Os resultados calculados das parcelas de calor de entrada e saída, Tabela 4, foram considerados válidos por apresentarem diferenças relativas baixas.

Tabela 4. Resultados dos cálculos das parcelas calor de entrada e saída, apurados nos dois balanços.

\begin{tabular}{|c|c|c|c|c|c|c|}
\hline & Variável & unidade & $\begin{array}{c}\text { Estudo } \\
\text { (A) }\end{array}$ & $\begin{array}{c}\text { Software } \\
\text { Balanço } \\
\text { (B) }\end{array}$ & $\begin{array}{c}\text { Diferença } \\
\text { (A-B) }\end{array}$ & $\begin{array}{l}\text { Diferença } \\
\text { \% relativa } \\
\text { ao total de } \\
\text { entrada } \\
(\%)\end{array}$ \\
\hline \multirow{7}{*}{ 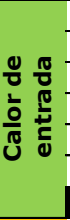 } & Calor de combustão total & $\mathrm{Mcal} / \mathrm{t}$ & 343,0 & 353,0 & $-10,0$ & $-2,5$ \\
\hline & Calor sensível no ar de combustão & $\mathrm{Mcal} / \mathrm{t}$ & 38,9 & 38,5 & 0,4 & 0,1 \\
\hline & Calor sensível no combustível & $\mathrm{Mcal} / \mathrm{t}$ & 0,1 & 0,3 & $-0,2$ & 0,0 \\
\hline & Calor sensível nas placas enfornadas & $\mathrm{Mcal} / \mathrm{t}$ & 2,9 & 1,8 & 1,2 & 0,3 \\
\hline & Calor de formação da carepa & $\mathrm{Mcal} / \mathrm{t}$ & 19,9 & 17,8 & 2,1 & 0,5 \\
\hline & Calor sensível no vapor & $\mathrm{Mcal} / \mathrm{t}$ & 1,3 & 3,0 & $-1,7$ & $-0,4$ \\
\hline & Total & & 406,1 & 414,4 & & \\
\hline \multirow{6}{*}{ 造 } & Calor sensível nas placas desenfornadas & $\mathrm{Mcal} / \mathrm{t}$ & 195,5 & 191,9 & 3,6 & 1,0 \\
\hline & Calor sensível na fumaça na saida do forno (base úmida) & $\mathrm{Mcal} / \mathrm{t}$ & 120,9 & 146,7 & $-25,8$ & $-6,9$ \\
\hline & Calor sensível na água de refrigeração & $\mathrm{Mcal} / \mathrm{t}$ & 38,5 & 40,0 & $-1,4$ & $-0,4$ \\
\hline & Calor perdido pelas paredes & $\mathrm{Mcal} / \mathrm{t}$ & 13,3 & 11,2 & 2,1 & 0,6 \\
\hline & Calor perdido pela carepa & $\mathrm{Mcal} / \mathrm{t}$ & 5,0 & 4,4 & 0,7 & 0,2 \\
\hline & Total & & 373,2 & 394,1 & & \\
\hline
\end{tabular}




\section{CONCLUSÃO}

Foi desenvolvido um software de cálculo automático do balanço térmico dos fornos de reaquecimento de placas da Usina de Ipatinga. Praticamente todos os dados necessários aos cálculos são buscados automaticamente em bancos de dados de processo, no PIMS, e de produto, no Oracle. Após a busca, os dados são validados e tratados convenientemente para serem usados como valores de entrada do cálculo do balanço térmico.

O software foi desenvolvido em ambiente de programação visual, em linguagem orientada a objetos, estando em linha com os avanços recentes em desenvolvimento de software.

Com isso, a execução do balanço térmico, que antes demandava vários dias de forma manual, pode ser feita com o software em minutos, com menor possibilidade de erros, em função da pouca interferência humana na coleta e tratamento dos dados, e realização dos cálculos. Ressalta-se ainda a superior qualidade de apresentação dos resultados.

Devido ao seu projeto de desenvolvimento, qualquer outro forno, além dos três da LTQ e dos dois da LCG já cadastrados, pode ser incluído no software do balanço térmico, uma vez que toda estrutura já está pronta.

Dessa forma, o software tem o potencial de contribuir significativamente para a redução do consumo de combustíveis nos fornos de reaquecimento.

\section{REFERÊNCIAS}

1 ANDRADE, HL, ROLDAN, A, HAUCK, GAC. Balanço térmico dos fornos de reaquecimento da Usiminas, Metalurgia ABM, 1983, 39(312): 27-31.

2 SANTOS, AA, TEIXEIRA, MH, MAIA, GA. Implementação de balanços térmicos on line nos fornos de reaquecimento da linha de tiras a quente da Usiminas, In: 43ํㅡㄴ Seminário de Laminação, ABM, Curitiba, outubro/2006.

3 SANTOS, A.A., OLIVEIRA, C.A.S., HAUCK, G.A.C., RIBEIRO, J.C., ROSA, J.H.A., LAIA, L.L., TEIXEIRA, M.H. Tecnologia de Fornos de Reaquecimento, Apostila de Curso de Fornos de Reaquecimento, Usiminas, 2002.

4 PI System Data Flow - OSI Software Inc. "PIMS - Process Information Management System - Uma introdução", Capítulo 6.

5 HEUSER, C A, Projeto de Banco de Dados. Editora Sagra Luzzato, 5a edição, 2004.

6 Material de Aula da Disciplina: Fundamentos de Armazenamento e Manipulação de Dados. - IME - Professor: Andre Rodrigo Sanches, acessado em 03/2015: http://www.ime.usp.br/ andrers/aulas/bd2005-1/aula5.html 